ceded last week that if, by some chance, nuclear generating costs were reduced to, say, $0 \cdot 35 d$ per unit, the $0.5 d$ foreseen for the fluidized combustion power station would look rather sick. But present forecasts of nuclear generating costs are still about $0.5 d$, and Mr Grainger was optimistic about the viability of fluidized combustion stations for the late 1970s. Nuclear power stations are also most economical on base-load operation, so that Mr Grainger says that there is bound to be a considerable demand for coal-produced power for peak usage.

Design and feasibility studies are at present under way for the construction of a prototype $20 \mathrm{MW}$ fluidized combustion generator using a 20 foot by 40 foot bed. A decision on whether to proceed with this prototype is expected later this year, and the NCB hopes then. to embark on its plans for a full scale $660 \mathrm{MW}$ station, probably at Grimethorpe in Yorkshire, for completion in 1976.

A test section 3 foot square has been built at Stoke Orchard, and the trials are considered encouraging. Research is also going on at the British Coal Utilization Research Association at Leatherhead on the possibility of using pressurized air to increase further the rate of heat flow in the furnace. About 80 per cent of the heat is extracted by water tubes in the bed, and 20 per cent by means of a gas turbine, and if the problem of excess waste material in the turbine can be overcome the pressurized process could bolster the economic saving in fluidized combustion still more.

An extra benefit of fluidized combustion is the reduction in sulphur dioxide emission which is already attracting American companies worried by the recent anti-pollution legislation. The sulphur dioxide is removed by the addition of a fine limestone to the furnace. It appears that the US National Air Pollution Control Administration has already allocated $\$ 20$ million for research on fluidized combustion. The NCB is devoting about $£ 0.5$ million to this project.

\section{FRUIT RESEARCH}

\section{Progress at Eust Malling}

\section{from our Botany Correspondent}

WHEN the Agricultural Research Council's Ditton Laboratory, once an outstation of the now defunct Low Temperature Research Station at Cambridge, ceased to exist on March 31, its staff and equipment were redeployed to other ARC institutes, principally the nearby East Malling Research Station. At the end of July, Dr H. C. Pereira takes over as director of the new merged organization, which has been formed as part of the ARC's efforts to end some of the duplication of activities in different research stations.

East Malling's contribution to the merger is a flourishing programme of research concerned with most aspects of fruit production. The latest annual report (price $21 s$, from East Malling Research Station) tells of some particularly important advances in the control of wilt disease in hops, which is caused by the fungus Verticillium albo-atrum. As well as the new resistant varieties of hops, 'Alliance' and 'Progress', there are signs that the disease could be controlled if farmers used less nitrogen fertilizer. Hops grown on experimental plots at East Malling were less infected with Verticillium, with no loss of yield, when the soil was treated with 60 and 120 units/acre of nitrogenous fertilizer rather than 180 units/acre. Hop farmers often put down between 180 and 240 units/acre of this fertilizer, and it looks as if they would be better advised to use less.

Another of the important activities at East Malling recently has been the screening of crops for viruses that produce no noticeable symptoms, although they may be having some adverse effect on growth and development. A survey of cherry trees in Kent, Berkshire and the West Midlands has revealed that British production of cherries is at least 30 per cent less than it could be if the trees were not so heavily infected with viruses.

With hops, too, the situation seems to be similar. Plants free from viruses can be grown from cultures of the stem tips, or meristems, and, compared with infected plants, they grow better in every respect. Healthy clones have also been produced from meristem cultures of strawberries, blackcurrants and gooseberries. The strawberries will be cropped for another year before they are released to the growers and the other two clones are ready for fruiting trials. Other work, with apples and cherries, has been so successful that after heat treatment both rootstocks and scions can be supplied free of viruses.

\section{POLICY \\ National Biology for Australia}

AUstralia's unique flora and fauna will be neglected no longer if the latest recommendation of the Australian Academy of Sciences is taken up by the Australian Government. A report made by the Academy's Flora and Fauna Committee Jast October-Proposal to Establish a Biological Survey of Australia-has just been published. It is the fruit of many visits to state museums and herbaria, which are at present responsible for the scientific study of local animals and plants.

The museums and herbaria are apparently doing valiant work, but they have meagre resources and are largely concerned with the situation in their own states, although flora and fauna do not recognize state boundaries. The proposed biological survey is envisaged as a national body, situated in Canberra, which will work closely with the state organizations, systematically to collect and describe animals and plants. There would be two divisions, zoological and botanical, and one of the objects of the botanical division would be to produce a new flora of Australia. The only comprehensive descriptive list of the plants of the continent now available was completed more than a hundred years ago, and deals with only a fraction of the plants now known in Australia.

The Academy of Sciences is hoping that the Government will act quickly to implement the recommendation, and remedy the present situation whereby Australia is the only advanced country in the world that has no national biological survey or equivalent institution. Australia, the committee's report says, is deplorably lacking in properly trained taxonomists, although adequate taxonomy is essential for advances in economically important subjects such as horticulture, pest control and the chemistry of natural products as well as pure biological research. The biological survey would be the solution to this lack of taxonomists. 